Bull. Chem. Soc. Ethiop. 2012, 26(1), 9-18.

Printed in Ethiopia

DOI: http://dx.doi.org/10.4314/bcse.v26i1.2

ISSN 1011-3924

(c) 2012 Chemical Society of Ethiopia

\title{
A NOVEL SEPARATION/PRECONCENTRATION TECHNIQUE BASED ON ULTRASONIC DISPERSION LIQUID-LIQUID MICROEXTRACTION FOR DETERMINATION OF TRACE COBALT BY FLAME ATOMIC ABSORPTION SPECTROMETRY
}

\author{
Yukun Wang ${ }^{1}$, Xiaojing $\mathrm{Ke}^{2}$, Jingwen Zhang ${ }^{1}, \mathrm{Xin} \mathrm{Du}^{1}$, Jingjun $\mathrm{Ma}^{1 *}$ and Jingci $\mathrm{Li}^{1 *}$ \\ ${ }^{1}$ Hebei Key Laboratory of Bioinorganic Chemistry, College of Science, Agricultural University \\ of Hebei, Baoding 071001, Hebei Province, P.R. China \\ ${ }^{2}$ Graduate School, Agricultural University of Hebei, Baoding 071001, Hebei Province, P.R. \\ China
}

(Received September 28, 2010; revised September 22, 2011)

\begin{abstract}
An improved method for the determination of trace cobalt in water samples has been developed using ultrasonic dispersion liquid-liquid microextraction (US-DLLME) prior to flame atomic absorption spectrometry (FAAS) analysis. In this method, cobalt was extracted into the fine droplets of carbon tetrachloride after chelate formation with the water soluble ligand, ammonium pyrrolidine dithiocarbamate (APDC). The fine droplets of carbon tetrachloride were formed and dispersed in the aqueous sample with the help of ultrasonic waves which accelerated the formation of the fine cloudy solution without using disperser solvents. Under optimum conditions, the calibration curve was linear in the range of $2.5-500 \mu \mathrm{g} \mathrm{L}^{-1}$, with a detection limit of 0.8 $\mu \mathrm{g} \mathrm{L}^{-1}$. The relative standard deviation (RSD) for ten replicate measurements of 20 and $500 \mu \mathrm{g} \mathrm{L}^{-1}$ of cobalt were 3.3 and $2.2 \%$. This proposed method was successfully applied to tap water, river water, and sea water, and accuracy was assessed through the analysis of certified reference water or recovery experiments. Operation simplicity, low cost, high enrichment factor, and low consumption of the extraction solvent are the main advantages of the proposed method.
\end{abstract}

KEY WORDS: Ultrasonic dispersion liquid-liquid microextraction, Preconcentration, Atomic absorption spectrometry, Cobalt

\section{INTRODUCTION}

Cobalt is a naturally occurring element found in rocks, soil, water, plants, and animals. It is an essential micronutrient required for the growth of both plants and animals [1]. Deficiency of cobalt leads to several diseases such as pernicious anemia [2]. On the other hand, large amounts of cobalt can produce toxicological effects including vasodilation, flushing and cardiomyopathy in humans and animals [3]. Therefore, the development of accurate and rapid determination methods for monitoring the level of cobalt concentration in the environmental samples is necessary and indispensable.

Flame atomic absorption spectrometry (FAAS) has been widely used for the determination of trace metal ions because of the relatively simple and inexpensive equipment required. However, direct determination of metal ions at trace levels by FAAS is limited, not only due to insufficient sensitivity, but also to matrix interference. Under these circumstances, in order to determine trace levels of $\mathrm{Co}$, a separation and enrichment step prior to the determinations may be beneficial. Several methods have been proposed for separation and preconcentration of trace Co, including liquid-liquid extraction (LLE) [4], coprecipitation [5], solid phase extraction (SPE) [6], and cloud point extraction (CPE) [7]. Each technique has its advantages and disadvantages and should be chosen according to the analytical problem.

Modern trends in analytical chemistry now lean towards the simplification and miniaturization of sample preparation, as well as the minimization of the organic solvent used.

*Corresponding author. E-mail: majingjun@hebau.edu.cn; jingcili63@yahoo.com.cn 
Jeannot and Cantwell developed a liquid-phase microextraction (LPME) technique in 1996, which was based on analyte partitioning between a drop of organic solvent (extraction phase) and a bulk aqueous sample [8]. Several different types of LPME have been developed, including single drop microextraction (SDME) [9], hollow fiber LPME [10], homogeneous liquid-liquid extraction (HLLE) [11], solidified floating organic drop microextraction (SFODME) [12] and coacervative microextraction [13]. Microextraction techniques are fast, simple, inexpensive, environmentally friendly, and compatible with many analytical instruments. Nevertheless, some drawbacks, such as instability of the droplet and relatively low precision, are often reported [14].

Recently, Assadi and co-workers developed a novel microextraction technique, termed dispersive liquid-liquid microextraction (DLLME) [15]. This technique is based on the formation of tiny droplets of the extractant in the sample solution using a water-immiscible organic solvent (extractant) dissolved in a water-miscible organic dispersive solvent [16, 17]. The advantages of the DLLME method are rapidity, low cost, and high enrichment factors. Its main drawback is the necessity of using a third component (disperser solvent), which usually decreases the partition coefficient of analytes into the extraction solvent [18].

Ultrasonic radiation is a powerful means for acceleration of various steps in analytical procedure for both solid and liquid samples [19]. This type of energy has also great help in the varied liquid-liquid extractive system because it facilitates the emulsification phenomenon and accelerates the mass-transfer process between two immiscible phases [20]. This leads to an increment in the extraction efficiency of the procedure in a minimum time [21]. In combination, DLLME system and ultrasound radiation provide an efficient preconcentration technique, termed ultrasonic dispersion liquid-liquid microextraction (US-DLLME), which is based on the implosion bubbles generated by the cavitation phenomenon, which produce intense shock waves in the surrounding liquid, resulting in high-velocity liquid jets. In the vicinity of collapsing bubbles, droplet disruption can be caused by these microjets and thus emulsification can be improved by a smaller droplet size of the dispersed phase generated by these microjets, immediately after droplet disruption [22, 23]. Submicron droplet size leads to significant enlargement of the contact surface between both immiscible liquids, improving the masstransfer between the phases [24].

In US-DLLME, the appropriate extraction solvent is rapidly injected by syringe into aqueous samples containing the analyte of interest. After sonication, a cloudy solution forms. This cloudy solution is then centrifuged and the fine droplets sediment at the bottom of the conical centrifuge tube. The determination of analytes in the sedimented phase can be performed by instrumental analysis. Operation simplicity, low cost, high enrichment factor, and low consumption of the extraction solvent are the main advantages of the proposed method.

The present paper describes the application of ultrasonic dispersion liquid-liquid microextraction for the determination of trace cobalt in water samples. In order to obtain a high enrichment factor, the effect of different parameters affecting the complex formation and extraction conditions (such as type and volume of the extraction solvent, $\mathrm{pH}$, the chelating agent amount, extraction time, extraction temperature and ionic strength) were tested.

\section{EXPERIMENTAL}

\section{Apparatus}

The determination was performed with a Hitachi Z-5000 atomic absorption spectrometer (Japan) equipped with Zeeman background correction. A cobalt hollow cathode lamp operating at $240.7 \mathrm{~nm}$ was utilized as the radiation source. The instrumental parameters were adjusted according to the manufacturer's recommendations. All $\mathrm{pH}$ measurements were carried out using a $\mathrm{pH}_{3}-3 \mathrm{C}$ digital $\mathrm{pH}$ meter equipped with a combined glass-calomel electrode (Hangzhou 
Dongxing Instrument Factory, Hangzhou, China). A Model LD5-2A centrifuge (Beijing Jingli Instrument Factory, Beijing, China) was used to accelerate the phase separation. A $59 \mathrm{kHz}, 200$ W ultrasonic bath with temperature control (Shanghai Kudos Ultrasonic instrument Co, Ltd., Shanghai, China) was used to assist the emulsification process of the microextraction technique.

\section{Reagents and solutions}

A stock standard solution of cobalt at a concentration of $1000 \mu \mathrm{g} \mathrm{mL^{-1 }}$ was purchased from the National Institute of Standards (Beijing, China). Working standard solutions were prepared by serial dilutions of the stock solution with deionized water immediately prior to analysis. The chelating agent, $0.2 \mathrm{~g} \mathrm{~L}^{-1}$ ammonium pyrrolidine dithiocarbamate (APDC), was prepared by dissolving the appropriate amount of APDC (Beijing Chemistry Reagent Company, Beijing, China) in deionized water. The $\mathrm{NaCl}$ solution was prepared by dissolving the appropriate amount of $\mathrm{NaCl}$ in deionized water. Carbon tetrachloride $\left(\mathrm{CCl}_{4}\right)$, chloroform $\left(\mathrm{CHCl}_{3}\right)$ and carbon disulfide $\left(\mathrm{CS}_{2}\right)$, as extraction solvents, were obtained from Tianjin Tianda Chemical Reagent Company (Tianjin, China).

Nitric acid $(0.1 \mathrm{M})$ was used to adjust the $\mathrm{pH} 2-3$, ammonium acetate buffers $(0.2 \mathrm{M})$ were prepared by adding an appropriate amount of acetic acid to ammonium acetate solutions resulting in solutions of $\mathrm{pH} 4-6$. For $\mathrm{pH} 7-8$, a phosphate $(0.2 \mathrm{M})$ buffer solution was prepared by adding an appropriate amount of disodium hydrogen phosphate to sodium dihydrogen phosphate. Ammonium chloride buffer solutions $(0.2 \mathrm{M})$ were prepared by adding an appropriate amount of ammonia to ammonium chloride solutions, resulting in solutions of $\mathrm{pH}$ 9-10.

All reagents used were of analytical reagent grade. Deionized water was used in the preparation of all solutions. The laboratory glassware was kept in $10 \%$ nitric acid for at least 24 $\mathrm{h}$ and subsequently washed four times with deionized water.

Tap, sea and river water samples used for development of the method were collected in polytetrafluoroethylene (PTFE) containers from Hebei province, filtered using a $0.45 \mu \mathrm{m}$ pore size membrane filter to remove suspended particulate matter, and stored in a refrigerator in the dark.

Ultrasonic dispersion liquid-liquid microextraction procedure

A $5.0 \mathrm{~mL}$ sample of standard solution containing $500 \mu \mathrm{g} \mathrm{L}^{-1}$ of cobalt was poured into a conical centrifuge tube. $1.0 \mathrm{~mL}$ acetate buffer and $2.0 \mathrm{~mL}$ APDC $\left(0.2 \mathrm{~g} \mathrm{~L}^{-1}\right)$ solution were added, then $80 \mu \mathrm{L}$ of carbon tetrachloride (extraction solvent) was injected rapidly into the sample solution using a syringe. The tube was immersed into an ultrasonic bath for $2 \mathrm{~min}$ at $45^{\circ} \mathrm{C}$. As a result, oil-in-water $(\mathrm{O} / \mathrm{W})$ emulsions of carbon tetrachloride in water were formed. Emulsions were then disrupted by centrifugation at $4600 \mathrm{rpm}$ for $2 \mathrm{~min}$, which resulted in the organic phase sedimentation at the bottom of the conical tube. The sedimented phase was quantitatively transferred to another test tube and the solvent was allowed to evaporate at room temperature.

Finally, the residue was dissolved in of $0.5 \mathrm{~mL} 0.1 \mathrm{M}$ nitric acid and the cobalt concentration was determined by flame atomic absorption spectrometry.

\section{RESULTS AND DISCUSSION}

\section{Effect of type and volume of the extraction solvent}

The extraction solvent should have special characteristics. It should have a higher density than water, high extraction capability for the compound of interest, and low solubility in water [25, 
26]. Carbon tetrachloride $\left(\mathrm{CCl}_{4}\right.$, density: $\left.1.59 \mathrm{~g} \mathrm{~mL}^{-1}\right)$, chloroform $\left(\mathrm{CHCl}_{3}\right.$, density: $\left.1.48 \mathrm{~g} \mathrm{~mL}^{-1}\right)$ and carbon disulfide $\left(\mathrm{CS}_{2}\right.$, density: $\left.1.26 \mathrm{~g} \mathrm{~mL}^{-1}\right)$ were examined in the present study for the extraction of cobalt. A series of sample solutions were studied by using different volumes of the extraction solvent to achieve a $60 \mu \mathrm{L}$ volume of the sedimented phase. Since the solubility of the extraction solvents in water is different, it was necessary to add an excess amount of extraction solvent, in order to recover a constant volume of the sedimented phase $(60 \mu \mathrm{L})$. Therefore, 80, 122 and $90 \mu \mathrm{L}$ of carbon tetrachloride, chloroform, and carbon disulfide were employed, respectively.

In this experiment chloroform, carbon disulfide, and carbon tetrachloride as extraction solvents resulted enrichment factors of $113 \pm 7,115 \pm 6$ and $118 \pm 5$, respectively. According to these results, variations in the enrichment factors using different extraction solvents were not statistically significant. In detail, carbon tetrachloride formed a stable, cloudy solution; the sedimented phase could easily be removed and had low consumption volume due to its low solubility. In contrast, chloroform forms an unstable cloudy solution and carbon disulfide is difficult to remove. Therefore, carbon tetrachloride was selected as the extraction solvent for further studies.

To examine the effect of the extraction solvent volume, solutions containing different volumes of carbon tetrachloride were subjected to the same US-DLLME procedures. As seen in Figure $1,80 \mu \mathrm{L}$ carbon tetrachloride was used as the optimum volume of the extraction solvent.

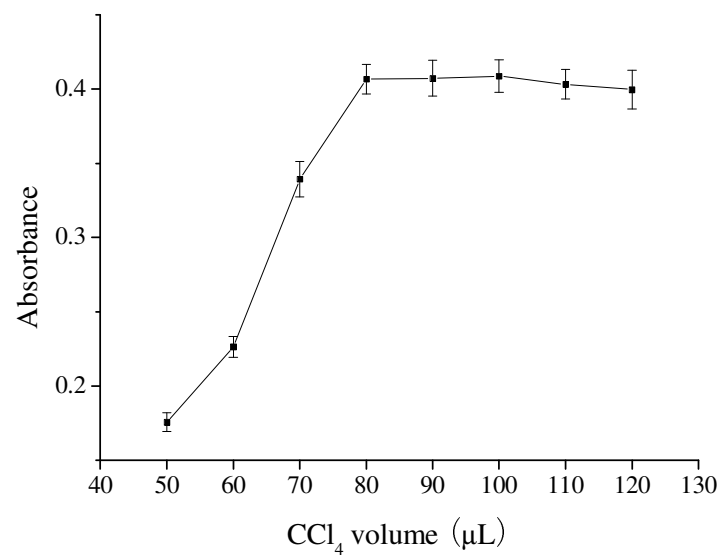

Figure 1. Effect of the volume of extraction solvent $\left(\mathrm{CCl}_{4}\right)$ on the absorbance of Co obtained from US-DLLME. Extraction conditions: water sample volume, $5.0 \mathrm{~mL}$; APDC volume, $2.0 \mathrm{~mL}$; $\mathrm{pH} 5.0$; concentration of $\mathrm{Co}, 500 \mu \mathrm{g} \mathrm{L}^{-1}$; extraction time, $2 \mathrm{~min}$; extraction temperature, $45^{\circ} \mathrm{C}$.

\section{Influence of $\mathrm{pH}$}

The separation of metal ions by US-DLLME involves prior formation of a complex with sufficient hydrophobicity to be extracted into the small volume of the sedimented phase, whereby the desired preconcentration is obtained. $\mathrm{pH}$ plays a unique role in metal-chelate formation and subsequent extraction. The effect of $\mathrm{pH}$ on the complex formation and extraction of cobalt from water samples was studied in the range of 2.0-10.0 using nitric acid, ammonium acetate, phosphate and ammonium chloride. As can be seen in Figure 2, the highest signal intensity of Co was obtained at $\mathrm{pH}$ 5.0. The progressive decrease in extraction of cobalt at low $\mathrm{pH}$ is due to competition of the hydrogen ion with the analyte for reaction with APDC. At 
higher $\mathrm{pH}$ values, the hydrolysis of cations occurs [27, 28]. Therefore, $\mathrm{pH} 5.0$ was selected for further study.

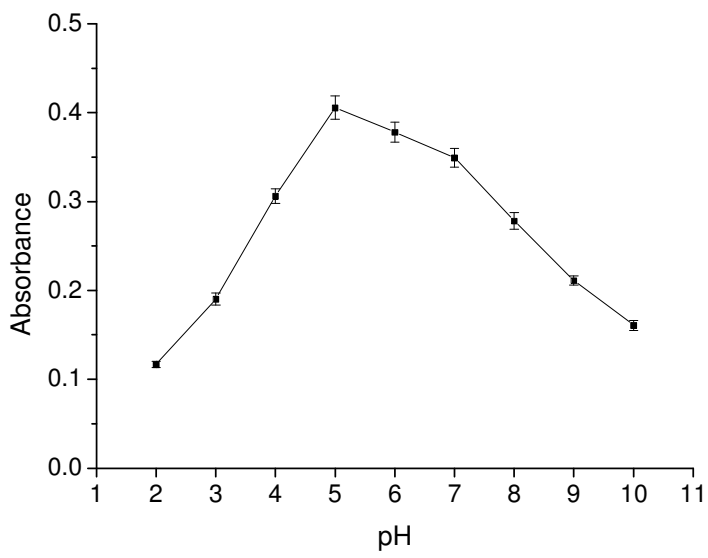

Figure 2. Effect of $\mathrm{pH}$ on the absorbance of Co obtained from US-DLLME. Extraction conditions: water sample volume, $5.0 \mathrm{~mL}$; APDC volume, $2.0 \mathrm{~mL}$; extraction solvent $\left(\mathrm{CCl}_{4}\right)$ volume, $80 \mu \mathrm{L}$; concentration of $\mathrm{Co}, 500 \mu \mathrm{g} \mathrm{L}^{-1}$; extraction time, $2 \mathrm{~min}$; extraction temperature, $45^{\circ} \mathrm{C}$.

Influence of the amount of APDC

The effect of the amount of APDC $\left(0.2 \mathrm{~g} \mathrm{~L}^{-1}\right)$ on the absorption was studied, and the results are shown in Figure 3. The amount of APDC was increased until the total extraction of Co was obtained. The absorbance was stable when the APDC volume was higher than $1.6 \mathrm{~mL}$, indicating complete complexation. When the amount of APDC was higher than $2.0 \mathrm{~mL}$, the analytical signal decreased. This effect is probably caused by competition between complexing agent molecules, which are in excess in the solution, and Co-complex molecules for extraction solvent interaction [7]. In this study, an APDC volume of $2.0 \mathrm{~mL}$ was chosen, in order to account for other extractable species that might potentially interference with the assaying of Co.

\section{Effect of the sonication time}

Dispersion is the key step to determine whether the extraction can be successfully carried out or not. Accordingly, sonication time plays an important role in US-DLLME procedure. Enough time will make the extracting solvent dispersed more finely into the aqueous solution and result in an excellent cloudy solution. So, the effect of sonication time was evaluated in the range of 0 $30 \mathrm{~min}$. The results showed that the signals of cobalt were increased by increasing the sonication time up to $2 \mathrm{~min}$. After $2 \mathrm{~min}$, the absorbance remained nearly constant. Thus, $2 \mathrm{~min}$ was selected as the working condition for further studies.

\section{Effect of extraction temperature}

Temperature affects organic solvent solubility in water as well as the emulsification phenomenon [29]. Thus, it also affects the mass-transfer process and the extraction efficiency. To determine the influence of the extraction temperature, a $5.0 \mathrm{~mL}$ aqueous solution containing $500 \mu \mathrm{g} \mathrm{\textrm {L } ^ { - 1 }}$ of cobalt was extracted at different temperatures, ranging from $20{ }^{\circ} \mathrm{C}$ to $70{ }^{\circ} \mathrm{C}$ 
(Figure 4). At temperatures lower than $35{ }^{\circ} \mathrm{C}$, it was difficult to get a homogeneous emulsion to allow a prompt phase separation. Therefore, the mass-transfer process was limited to a short time period, leading to poor extraction efficiency, and consequently low Co recovery. In the 35$55^{\circ} \mathrm{C}$ temperature range, the emulsification was easily achieved and the highest absorbance was obtained at $45{ }^{\circ} \mathrm{C}$. At a temperature higher than $55^{\circ} \mathrm{C}$, the analytical signal decreased significantly. This may be due to an increase in solubility of the organic phase and the degradation of the complex brought about by high temperatures. Hence, $45{ }^{\circ} \mathrm{C}$ is recommended for further studies.

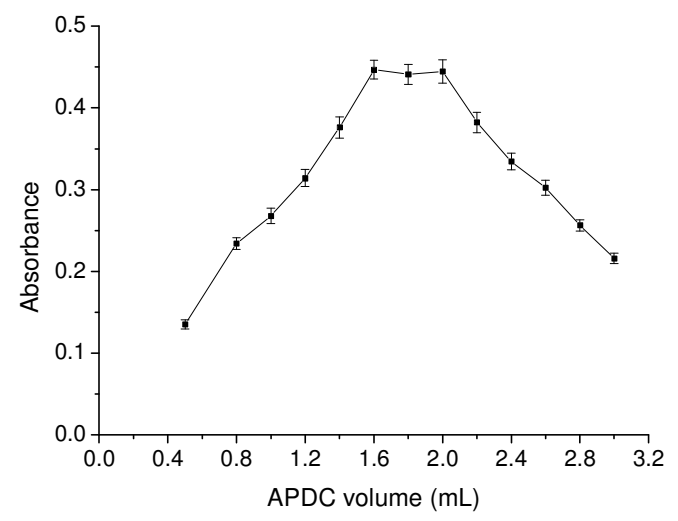

Figure 3. Effect of APDC volume on the absorbance of Co obtained from US-DLLME. Extraction conditions: water sample volume, $5.0 \mathrm{~mL} ; \mathrm{pH} 5.0$; extraction solvent $\left(\mathrm{CCl}_{4}\right)$ volume, $80 \mu \mathrm{L}$; concentration of $\mathrm{Co}, 500 \mu \mathrm{g} \mathrm{L}^{-1}$; extraction time, $2 \mathrm{~min}$; extraction temperature, $45^{\circ} \mathrm{C}$.

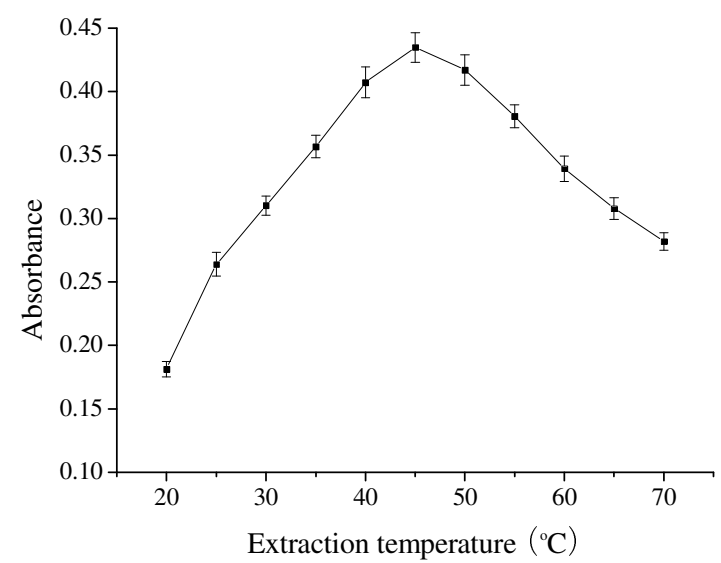

Figure 4. Effect of extraction temperature on the absorbance of Co obtained from US-DLLME. Extraction conditions: water sample volume, $5.0 \mathrm{~mL} ; \mathrm{pH} 5.0$; extraction solvent $\left(\mathrm{CCl}_{4}\right)$ volume, $80 \mu \mathrm{L}$; concentration of $\mathrm{Co}, 500 \mu \mathrm{g} \mathrm{L}{ }^{-1}$; extraction time, 2 min.

Effect of salt

To investigate the influence of ionic strength on the efficiency of US-DLLME, various experiments were performed by adding varying $\mathrm{NaCl}$ amounts from $0 \%$ to $5 \%(\mathrm{w} / \mathrm{v})$. Other

Bull. Chem. Soc. Ethiop. 2012, 26(1) 
experimental conditions were kept constant. As the $\mathrm{NaCl}$ concentration increased, the volume of the sedimented phase increased slightly, from $60 \mu \mathrm{L}$ to $63 \mu \mathrm{L}$. The results showed that salt addition had no significant effect on the enrichment factor, perhaps because of the two opposite effects of salt addition in US-DLLME of cobalt: one involves increasing the volume of the sedimented phase, which decreases the enrichment factor, and the other is the salting-out effect that increases the enrichment factor [30,31]. Therefore, the enrichment factor is held nearly constant by increasing the amount of sodium chloride. Subsequent extraction experiments were therefore carried out without additional salt.

\section{Effect of coexisting ions}

Most common matrix constituents of real samples such as alkali and alkaline earth elements do not react with APDC because of its selectivity [31]. However, large amounts of metal ions which react with APDC appreciably reduce the efficiency of cobalt extraction. The effect of potential ions, encountered in natural water samples, on the recovery of $500 \mu \mathrm{g} \mathrm{L}^{-1}$ cobalt standard solution in the presence of various amounts of individual interfering ions, was examined. For this purpose, the proposed US-DLLME-FAAS method under the optimum conditions was adopted while a variation on the recovery greater than $\pm 5 \%$ was considered as interference. The results are presented in Table 1. As can be seen, the common cations and anions present in natural water possess no adverse effects on the assaying of Co.

Table 1. Effect of coexisting ions on the determination of $500 \mu \mathrm{g} \mathrm{L}^{-1}$ Co in water samples.

\begin{tabular}{|c|c|c|c|}
\hline Interferent & Concentration $\left(\mu \mathrm{g} \mathrm{L}^{-1}\right)$ & Interferent $/ \mathrm{Co}^{2+}$ ratio & Recovery $(\%)$ \\
\hline $\mathrm{Na}^{+}$ & 5000,000 & 10000 & 96.5 \\
\hline $\mathrm{K}^{+}$ & 5000,000 & 10000 & 95.7 \\
\hline $\mathrm{Ca}^{2+}$ & 500,000 & 1000 & 98.3 \\
\hline $\mathrm{Mg}^{2+}$ & 500,000 & 1000 & 98.7 \\
\hline $\mathrm{Ag}^{+}$ & 50,000 & 100 & 96.3 \\
\hline $\mathrm{Ba}^{2+}$ & 50,000 & 100 & 95.3 \\
\hline $\mathrm{Mn}^{2+}$ & 30,000 & 60 & 96.2 \\
\hline $\mathrm{Cu}^{2+}$ & 30,000 & 60 & 97.2 \\
\hline $\mathrm{Zn}^{2+}$ & 30,000 & 60 & 97.7 \\
\hline $\mathrm{Al}^{3+}$ & 30,000 & 60 & 100.4 \\
\hline $\mathrm{Fe}^{3+}$ & 30,000 & 60 & 98.5 \\
\hline $\mathrm{Cd}^{2+}$ & 25,000 & 50 & 96.2 \\
\hline $\mathrm{Fe}^{2+}$ & 25,000 & 50 & 97.4 \\
\hline $\mathrm{Bi}^{3+}$ & 25,000 & 50 & 96.4 \\
\hline $\mathrm{As}^{5+}$ & 25,000 & 50 & 96.7 \\
\hline $\mathrm{Sn}^{4+}$ & 25,000 & 50 & 98.5 \\
\hline $\mathrm{Ni}^{2+}$ & 20,000 & 40 & 98.6 \\
\hline $\mathrm{Cr}^{3+}$ & 20,000 & 40 & 95.5 \\
\hline $\mathrm{Pb}^{2+}$ & 20,000 & 40 & 97.6 \\
\hline $\mathrm{Hg}^{2+}$ & 15,000 & 30 & 95.7 \\
\hline $\mathrm{As}^{3+}$ & 10,000 & 20 & 97.5 \\
\hline $\mathrm{Cl}^{-}$ & 5000,000 & 10000 & 99.2 \\
\hline $\mathrm{NO}_{3}^{-}$ & 5000,000 & 10000 & 100.4 \\
\hline $\mathrm{CH}_{3} \mathrm{COO}^{-}$ & 500,000 & 1000 & 97.1 \\
\hline $\mathrm{SO}_{4}^{2-}$ & 50,000 & 100 & 95.8 \\
\hline $\mathrm{Cr}_{2} \mathrm{O}_{7}{ }^{2-}$ & 50,000 & 100 & 96.2 \\
\hline $\mathrm{PO}_{4}{ }^{3-}$ & 50,000 & 100 & 95.4 \\
\hline
\end{tabular}


Analytical figures of merit

Using the optimum conditions, a calibration curve was obtained by preconcentrating a series of solutions according to procedure described. Table 2 shows the analytical characteristics of this method. The calibration curve was linear in the range of $2.5-500 \mu \mathrm{g} \mathrm{L}^{-1}$ cobalt. The equation for the calibration curve after the preconcentration procedure was given as $\mathrm{A}=1.33 \times 10^{-3} \mathrm{C}+$ 0.0167 with a correlation coefficient of $0.9984(\mathrm{n}=10)$, where $\mathrm{A}$ is the atomic absorbance for cobalt in the rich phase at $240.7 \mathrm{~nm}$ and $\mathrm{C}$ is the concentration of cobalt in the sample solution in $\mu \mathrm{g} \mathrm{L}^{-1}$. The limit of detection and quantification defined as $3 \mathrm{~S}_{\mathrm{B}} / \mathrm{m}$ and $10 \mathrm{~S}_{\mathrm{B}} / \mathrm{m}$ (where $\mathrm{S}_{\mathrm{B}}$ is standard deviation of the blank and $\mathrm{m}$ is the slope of the calibration curve) were 0.8 and $2.5 \mu \mathrm{g}$ $\mathrm{L}^{-1}$, respectively. The relative standard deviation (RSD) for ten replicate measurements of 20 and $500 \mu \mathrm{g} \mathrm{L}^{-1}$ of cobalt were 3.3 and $2.2 \%$. Table 2 also shows the calibration obtained with standard solutions of Co not subjected to the US-DLLME preconcentration step.

The enhancement factor [32,33], defined as the ratio of the slope of the calibration curve for the US-DLLME method, to that of the calibration curve in water phase without preconcentration, was 13.2.

Table 2. Analytical characteristics of the method.

\begin{tabular}{|l|c|c|}
\hline Analytical parameters & Without US-DLLME preconcentration & $\begin{array}{c}\text { With US-DLLME } \\
\text { preconcentration }\end{array}$ \\
\hline Linear range $\left(\mu \mathrm{g} \mathrm{L}^{-1}\right)$ & $150-6000$ & $2.5-500$ \\
\hline Slope & $1.01 \times 10^{-4}$ & $1.33 \times 10^{-3}$ \\
\hline Intercept & 0.0068 & 0.0167 \\
\hline Correlation coefficient & 0.9991 & 0.9984 \\
\hline Detection limit $\left(\mu \mathrm{g} \mathrm{L}^{-1}\right)$ & 12.5 & 0.8 \\
\hline Limit of quantification $\left(\mu \mathrm{g} \mathrm{L}^{-1}\right)$ & 41.6 & 2.5 \\
\hline Relative standard deviation & $3.7\left(200 \mu \mathrm{g} \mathrm{L}^{-1}\right)$ & $3.3\left(20 \mu \mathrm{g} \mathrm{L}^{-1}\right)$ \\
\hline RSD\%) $(\mathrm{n}=10)$ & $3.3\left(500 \mu \mathrm{g} \mathrm{L}^{-1}\right)$ & $2.2\left(500 \mu \mathrm{g} \mathrm{L}^{-1}\right)$ \\
\hline The enhancement factor & - & 13.2 \\
\hline
\end{tabular}

a The enhancement factor is the slope ratio of calibration curve after and before extraction.

Table 3. Analytical results of cobalt determination (dissolved fraction) in certified reference material and spiked natural water samples with the US-DLLME-FAAS method $(n=3)$.

\begin{tabular}{|c|c|c|c|c|}
\hline Sample & Certified & Added & Found $^{\mathrm{a}}$ & Recovery $(\%)$ \\
\hline \multirow{2}{*}{$\begin{array}{l}\text { GSBZ 50030-94 } \\
\left(\mu \mathrm{g} \mathrm{L}^{-1}\right)\end{array}$} & $14.4 \pm 1.0$ & - & $13.4 \pm 0.7$ & 93.1 \\
\hline & $28.8 \pm 2.0$ & - & $27.4 \pm 1.6$ & 95.2 \\
\hline \multirow{3}{*}{$\begin{array}{c}\text { Tap water } \\
\left(\mu \mathrm{g} \mathrm{L}^{-1}\right)\end{array}$} & & 0.0 & $<0.8$ & - \\
\hline & & 10.0 & $9.6 \pm 0.5$ & 96.0 \\
\hline & & 20.0 & $20.1 \pm 0.6$ & 100.5 \\
\hline \multirow{3}{*}{$\begin{array}{l}\text { Sea water } \\
\left(\mu \mathrm{g} \mathrm{L}^{-1}\right)\end{array}$} & & 0.0 & $4.8 \pm 0.2$ & - \\
\hline & & 5.0 & $9.5 \pm 0.4$ & 94.0 \\
\hline & & 10.0 & $14.6 \pm 0.5$ & 98.0 \\
\hline \multirow{3}{*}{$\begin{array}{l}\text { River water }{ }^{\mathrm{d}} \\
\qquad\left(\mu \mathrm{g} \mathrm{L}^{-1}\right)\end{array}$} & & 0.0 & $<0.8$ & - \\
\hline & & 10.0 & $9.5 \pm 0.6$ & 95.0 \\
\hline & & 20.0 & $20.3 \pm 0.6$ & 101.5 \\
\hline \multirow{2}{*}{$\begin{array}{l}\text { River water } \\
\quad\left(\mu \mathrm{g} \mathrm{L}^{-1}\right)\end{array}$} & & 0.0 & $3.8 \pm 0.2$ & - \\
\hline & & 5.0 & $8.4 \pm 0.3$ & 92.0 \\
\hline
\end{tabular}

${ }^{\mathrm{a}}$ Mean of three experiments \pm standard deviation. ${ }^{\mathrm{b}}$ From drinking water system of Baoding, China. ${ }^{\mathrm{c}}$ Beidaihe sea water, Qinhuangdao, China. ${ }^{\mathrm{d}}$ Yongding river water, Baoding, China. ${ }^{\mathrm{e}}$ Tang river water, Baoding, China. 


\section{Analysis of natural waters}

The proposed method was used for the determination of cobalt in several water samples and the results along with the recovery for the spiked samples were given in Table 3 . The recoveries for the addition of different concentrations of cobalt to water samples were in the range 92.0$101.5 \%$. To verify the accuracy of the proposed procedure, the method was then used for the determination of the content of Co in National Standard Reference Material for Environmental Water (GSBZ 50030-94) after the appropriate dilution. These results are presented in Table 3. A good agreement between the determined values and the certified values was obtained.

\section{Comparison to other methods}

A comparison of the represented method with other reported preconcentration methods [34-37] is given in Table 4. Generally, the RSD and the LOD obtained from the present method are comparable to or better than those reported methods. A lower enrichment factor could be the result of the smaller volume of sample compared with sample volume adopted in other reported preconcentration methods. However, US-DLLME requires much shorter extraction time than those for most of the other methods, which is better able to meet the needs of rapidity analysis. Furthermore, without the addition of the dispersive solvent, thereby the methodology overcomes DLLME disadvantages, which are of key interest for routine laboratories in trace metal ion analysis.

Table 4. Characteristic performance data obtained by using US-DLLME and other techniques in determination of cobalt in water.

\begin{tabular}{|l|c|c|c|c|c|c|c|}
\hline Method & $\begin{array}{c}\text { LOD } \\
\left(\mu \mathrm{g} \mathrm{L}^{-1}\right)\end{array}$ & $\begin{array}{c}\text { R.S.D. } \\
(\%)\end{array}$ & $\begin{array}{c}\text { Enrichment } \\
\text { factor }\end{array}$ & $\begin{array}{c}\text { Eextraction } \\
\text { time } \\
(\mathrm{min})\end{array}$ & $\begin{array}{c}\text { Sample } \\
\text { Consumptio } \\
\mathrm{n}(\mathrm{mL})\end{array}$ & $\begin{array}{c}\text { Calibration } \\
\text { range } \\
\left(\mu \mathrm{L} \mathrm{L}^{-1}\right)\end{array}$ & References \\
\hline CPE-FAAS & 5 & 1.71 & $20^{\mathrm{a}}$ & 10 & 10 & $0-200$ & 34 \\
\hline SPE-FAAS & 2.5 & 3.8 & $50^{\mathrm{b}}$ & 10 & 50 & - & 35 \\
\hline Coprecipitation-FAAS & 0.86 & $<10$ & $25^{\mathrm{b}}$ & 10 & 50 & - & 36 \\
\hline DLLME-FAAS & 0.9 & $2.3-5.8$ & $16^{\mathrm{c}}$ & $<1$ & 7 & $3-100$ & 37 \\
\hline US-DLLME-FAAS & 0.8 & 2.2 & $13.2^{\mathrm{c}}$ & 2 & 8 & $2.5-500$ & $\begin{array}{c}\text { Present } \\
\text { method }\end{array}$ \\
\hline
\end{tabular}

${ }^{\mathrm{a}}$ Preconcentration factor, as the ratio of the concentration of analyte after preconcentration to that without preconcentration giving the same analytical response. ${ }^{b}$ Ratio of the aqueous phase to final volume of eluent phase. ${ }^{\mathrm{c}}$ The enhancement factor is the slope ratio of calibration curve after and before extraction.

\section{CONCLUSIONS}

US-DLLME, combined with the flame atomic absorption spectrometry (FAAS), was evaluated for the preconcentration and the determination of the trace amounts of cobalt (at $\mu \mathrm{g} \mathrm{L}^{-1}$ level) from water samples. A high enrichment factor was easily obtained using this method. In addition, it is important to point out that US-DLLME is a low organic solvent consuming extraction technique, which turns it into a low cost and also an environmentally friendly technique. With this method, the consumption of toxic organic solvent (at the microliter level) was minimized without affecting the method sensitivity. US-DLLME is a technique that can be employed with satisfactory results as a simple and efficient extraction and preconcentration procedure for heavy metals in aqueous samples.

\section{ACKNOWLEDGEMENTS}

This project was sponsored both by Development Foundation of the Department of Education of Hebei Province, P.R. China (ZH2011128), and the Research Development Foundation of the Agricultural University of Hebei. 


\section{REFERENCES}

1. Lemos, V.A.; da Franca, R.S.; Moreira, B.O. Sep. Purif. Technol. 2007, 54, 349.

2. Agency for Toxic Substances and Disease Registry (ATSDR) Toxicological Profile for Cobalt, U.S. Department of Health and Human Services: Atlanta; 2001.

3. Chen, J.R.; Teo, K.C. Anal. Chim. Acta 2001, 434, 325.

4. Boukraa, Y.; Barkat, D.; Benabdellah, T.; Tayeb, A.; Kameche, M. Phys. Chem. Liq. 2006, 44, 693.

5. Divrikli, U.; Elci, L. Anal. Chim. Acta 2002, 452, 231.

6. Yamini, Y.; Hosseini, M.H.; Morsali, A. Microchim. Acta 2004, 146, 67.

7. Nascentes, C.C.; Arruda, M.A.Z. Talanta 2003, 61, 759.

8. Jeannot, M.A.; Cantwell, F.F. Anal. Chem. 1996, 68, 2236.

9. Fragueiro, S.; Lavilla, I.; Bendicho, C. Talanta 2006, 68, 1096.

10. Carletto, J.S.; Luciano, R.M.; Bedendo, G.C.; Carasek, E. Anal. Chim. Acta 2009, 638, 45.

11. Farajzadeh, M.A.; Bahram, M.; Zorita, S.; Mehr, B.G. J. Hazard. Mater. 2009, 161, 1535.

12. Dadfarnia, S.; Salmanzadeh, A.M.; Shabani, A.M.H. Anal. Chim. Acta 2008, 623, 163.

13. Fontana, A.R.; Camargo, A.B.; Altamirano, J.C. J. Chromatogr. A 2010, 1217, 6334.

14. Xu, L.; Basheer, C.; Lee, H.K. J. Chromatogr. A 2007, 1152, 184.

15. Rezaee, M.; Assadi, Y.; Hosseini, M.R.M.; Aghaee, E.; Ahmadi, F.; Berijani, S. J. Chromatogr. A 2006, 1116, 1.

16. Liang, P.; Sang, H.B. Anal. Biochem. 2008, 380, 21.

17. Anthemidis, A.N.; Ioannou, K.I.G. Talanta 2009, 79, 86.

18. Regueiro, J.; Llompart, M.; Garcia-Jares, C.; Garcia-Monteagudo, J.C.; Cela R. J. Chromatogr. A 2008, 1190, 27.

19. Aydin, M.E.; Tor, A.; Ozcan, S. Anal. Chim. Acta 2006, 577, 232.

20. Ozcan, S.; Tor, A.; Aydin, M.E. Anal Chim Acta 2009, 647, 182.

21. Luque de Castro, M.D.; Priego-Capote, F. Analytical Applications of Ultrasound, Elsevier: Amsterdam; 2006.

22. Fontana, A.R.; Wuilloud, R.G.; Martínez, L.D.; Altamirano, J.C. J. Chromatogr. A 2009, $1216,147$.

23. Fontana, A.R.; de Toro, M.M.; Altamirano, J.C. J. Agric. Food Chem. 2010, in press, doi: 10.1021/jf104622x.

24. Fontana, A.R.; Wuilloud, R.G.; Martinez, L.D.; Altamirano, J.C. J. Chromatogr. A 2009, 1216, 147.

25. Fontana, A.R.; Altamirano, J.C. Talanta 2010, 81, 1536.

26. Yao, L.X.; Jung, S. J. Agric. Food Chem. 2010, 58, 4866.

27. Bidabadi, M.S; Dadfarnia, S; Haji Shabani, A.M. J. Hazard. Mater. 2009, 166, 291.

28. Ma, J.J.; Zhang, J.W.; Du, X.; Lei, X.; Li, J.C. Microchim. Acta 2010, 168, 153.

29. Ma, J.J.; Du, X.; Zhang, J.W.; Li, J.C.; Wang, L.Z. Talanta 2009, 80, 980.

30. Jahromi, E.Z.; Bidari, A.; Assadi, Y.; Hosseini, M.R.M.; Jamali, M.R. Anal. Chim. Acta 2007, 585, 305.

31. Bidari, A.; Zeini Jahromi, E.; Assadi, Y.; Hosseini, M.R.M. Microchem. J. 2007, 87, 6.

32. Shemirani, F.; Kozani, R.R.; Assadi Y. Microchim. Acta 2007, 157, 81.

33. Fan, Z.F. Microchim. Acta 2005, 152, 29.

34. Giokas D.L.; Paleologos, E.K.; Tzouwara-Karayanni, S.M.; Karayannis M.I. J. Anal. At. Spectrom. 2001, 16, 521.

35. Karatepe, A.U.; Soylak, M.; Elci, L. Anal. Lett. 2002, 35, 2363.

36. Soylak, M.; Kaya, B.; Tuzen, M. J. Hazard. Mater. 2007, 147, 832.

37. Baliza, P.X.; Teixeira L.S.G.; Lemos, V.A. Microchem J. 2009, 93, 220. 